Technological University Dublin

DƯBLIN

ARROW@TU Dublin

$2005-1$

\title{
Investigation of Polymerization Rate in an Acrylamide-based Photopolymer using Raman Spectroscopy
}

Raghavendra Jallapuram

Technological University Dublin

Izabela Naydenova

Technological University Dublin, izabela.naydenova@tudublin.ie

Hugh Byrne

Technological University Dublin, hugh.byrne@tudublin.ie

See next page for additional authors

Follow this and additional works at: https://arrow.tudublin.ie/cieocon2

Part of the Optics Commons

\section{Recommended Citation}

Jallapuram, R., Naydenovaet, I. \& Byrne, H.J. (2005). Investigation of polymerization rate in acrylamidebased photopolymer for holographic recording. SPIE Proceedings of Opto-Ireland Conference, vol. 5826, pg. 75-82. doi:10.1117/12.605416

This Conference Paper is brought to you for free and open access by the Centre for Industrial and Engineering Optics at ARROW@TU Dublin. It has been accepted for inclusion in Conference Papers by an authorized administrator of ARROW@TU Dublin. For more information, please contact arrow.admin@tudublin.ie, aisling.coyne@tudublin.ie, gerard.connolly@tudublin.ie.

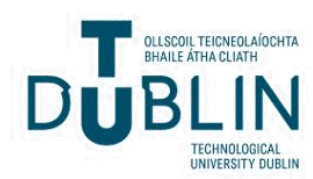




\section{Authors}

Raghavendra Jallapuram, Izabela Naydenova, Hugh Byrne, Suzanne Martin, Robert Howard, and Vincent Toal 
2005-01-01

\section{Investigation of polymerization rate in an acrylamide-based photopolymer using Raman spectroscopy}

Raghavendra Jallapuram

Dublin Institute of Technology

Izabela Naydenova

Dublin Institute of Technology, izabela.naydenova@dit.ie

Hugh Byrne

Dublin Institute of Technology, Hugh.byrne@dit.ie

Suzanne Martin

Dublin Institute of Technology, suzanne.martin@dit.ie

Robert Howard

Dublin Institute of Technology, robert.howard@dit.ie

See next page for additional authors

\section{Recommended Citation}

R. Jallapuram, I. Naydenova, H. J. Byrne, S. Martin, R. G. Howard, V. Toal, "Investigation of polymerization rate in acrylamide-based photopolymer for holographic recording”, SPIE proceedings of Opto-Ireland conference, V.5826, 75-82, 2005.doi:10.1117/

12.605416 
Authors

Raghavendra Jallapuram, Izabela Naydenova, Hugh Byrne, Suzanne Martin, Robert Howard, and Vincent Toal 


\title{
Investigation of polymerization rate in an acrylamide-based photopolymer using Raman spectroscopy
}

\author{
Raghavendra Jallapuram, Izabela Naydenova, Hugh J. Byrne², \\ Suzanne Martin, Robert G. Howard ${ }^{1}$, Vincent Toal \\ Center for Industrial and Engineering Optics \\ Dublin Institute of Technology, Kevin Street, Dublin-8. \\ 1) School of Physics, Dublin Institute of Technology, Kevin Street, Dublin-8. \\ 2) FOCAS Institute, Dublin Institute of Technology, Kevin Street, Dublin-8. \\ Telephone: +3531 4027926, Fax: +35314027901. \\ Email: j.raghavendra@dit.ie
}

\begin{abstract}
Diffusion models predict that polymerization and diffusion rates are the key factors that control the dynamics and the final properties of a holographic grating recorded in a photopolymerizable material. Diffusion rates during the initial phase of the holographic recording have already been studied and reported. We now report the investigation of the polymerization rate in an acrylamide-based photopolymer using Raman spectroscopy. The polymerization rate constant was estimated by monitoring the intensity of the characteristic Raman peaks at $1284 \mathrm{~cm}^{-1}$ corresponding to the bending mode of $\mathrm{CH}$ vinyl bond in acrylamide and $1609 \mathrm{~cm}^{-1}$ corresponding to the carbon-carbon double bond $(\mathrm{C}=\mathrm{C})$ in acrylamide as a function of illumination time. The dependence of the residual monomer concentration on the exposure time was fitted using a mono exponential fitting function. The value of the polymerization constant was estimated to be $0.043 \mathrm{~s}^{-1}\left(\mathrm{~mW} / \mathrm{cm}^{2}\right)^{-0.5}$ for this formulation.
\end{abstract}

A comparison with some other photopolymer systems reported in the literature reveals that the acrylamide-based photopolymer system is characterized by a relatively fast polymerization rate constant. The results from the present study give significant information for better understanding of the process of holographic recording in acrylamide-based photopolymer system.

Keywords: Photopolymer, polymerization rate, acrylamide.

\section{INTRODUCTION}

Photopolymers are attractive materials for the production of high quality holographic optical elements [1], holographic data storage [2-4] and interferometry [1] etc. Besides the advantage of being self-developing, photopolymers have high sensitivity, large dynamic range, good optical properties, low cost and are easy to prepare with a capability of recording high diffraction efficiency holograms.

Photopolymer systems for recording holograms typically comprise one or more monomers, a photoinitiator, a binder and a sensitizing dye. Several theoretical models have been used to describe the mechanism of hologram recording in photopolymers [5-12]. Most of the models proposed are based on diffusion of monomer or mass transport when a concentration gradient of monomer is created. The basic mechanism of the hologram recording in dye sensitized photopolymers is that a dye absorbs the energy of a photon and enters to into an excited state, whereupon it reacts with an electron donor to create free radicals. These free radicals initiate the polymerization reaction. As a result of this a concentration gradient of the monomer occurs, resulting in monomer diffusion from higher concentration regions to lower concentration regions.

Diffusion models predict that the key factor that controls the dynamics of hologram recording and the final properties of the hologram is the ratio of the diffusion and polymerization rates. The diffusion process is a spatially dependent process whereas the polymerization process is intensity dependent. Some of the earlier models [7-9] assumed that the polymerization rate, which is the rate of conversion of monomer into polymer by polymerization, has a linear 
A $514 \mathrm{~nm}$ Ar-ion green laser was used to expose the photopolymer layer. As the system under study was insensitive to $633 \mathrm{~nm}$, to avoid any additional changes in the sample during the measurement a He-Ne laser (633 nm) with a maximum power of $20 \mathrm{~mW}$ integrated in an Instruments SA LABRAM 1B Raman spectroscope system was used to acquire the vibrational Raman spectrum of the photopolymer sample. This also facilitated in situ measurements.

The samples were exposed to an intensity of $2.5 \mathrm{~mW} / \mathrm{cm}^{2}(514.5 \mathrm{~nm})$ over $1 \mathrm{~cm}^{2}$ spot. As soon as the layer is exposed the polymerization reaction starts, thus consuming the monomer. The intensities were similar to those used during the holographic 2-beam recording in this photopolymer. The $514 \mathrm{~nm}$ laser spot was overlapped with the $633 \mathrm{~nm}$ Raman laser $(\sim 2 \mu \mathrm{m}$ diameter). During the polymerization process carbon-carbon vinyl double bonds $(\mathrm{C}=\mathrm{C})$ are broken and are converted to single bonds $(C-C)$. The $C=C$ peak for the vinyl double bond was identified at $1630 \mathrm{~cm}^{-1}$ and the carbonhydrogen bond $(\mathrm{C}-\mathrm{H})$ bending mode peak was identified at $1284 \mathrm{~cm}^{-1}$ in an acrylamide only sample as reported by other authors $[15,16]$ and from the Raman spectrum of acrylamide. On polymerization the peak intensities corresponding to the carbon-carbon double $(\mathrm{C}=\mathrm{C})$ bond and the bend mode of the carbon-hydrogen $(\mathrm{CH})$ bond, both decrease. The Raman spectrum was measured as a function of illumination time following constant exposure doses of $5 \mathrm{~mJ} / \mathrm{cm}^{2}$.

\section{RESULTS AND DISCUSSIONS}

Raman spectra of acrylamide only and of the photopolymer system with other components, were acquired on the Raman spectrometer. The spectra are shown in figures 2 and 3 respectively.

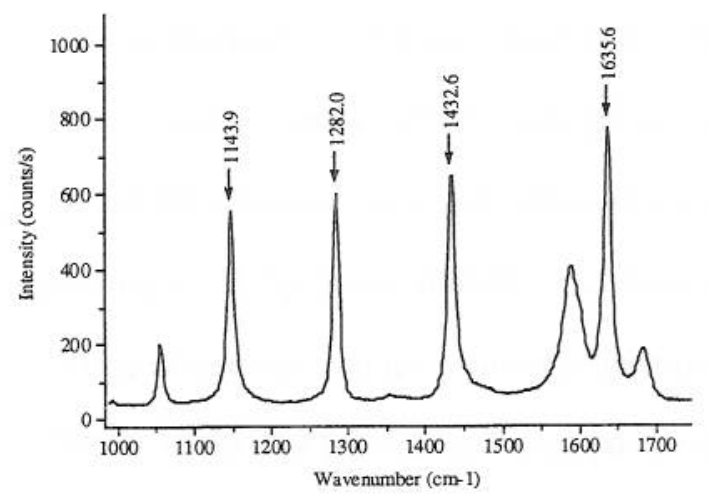

Figure 2. Raman spectrum of acrylamide monomer

$1000-1800 \mathrm{~cm}^{-1} \cdot \mathrm{C}=\mathrm{C}$ peak of monomer at $1635 \mathrm{~cm}^{-1}$

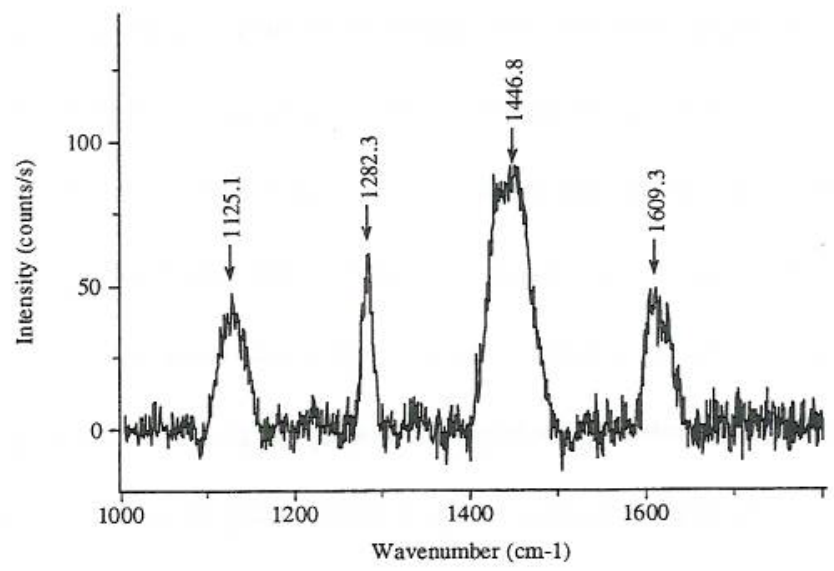

Figure 3. Raman spectrum of unexposed photopolymer layer 
From the two figures we observe that the carbon-carbon double bond $(\mathrm{C}=\mathrm{C})$ in the spectrum of acrylamide powder is centered at $\sim 1635 \mathrm{~cm}^{-1}$. In the photopolymer system the carbon-carbon double bond is broadened considerably and has primary maximum at $1609 \mathrm{~cm}^{-1}$. When the photopolymer layer is irradiated, the intensity of the acrylamide peak decreases concurrently. Figure 4 shows the Raman spectrum of the photopolymer layer exposed to a laser intensity of $2.5 \mathrm{~mW} / \mathrm{cm}^{2}$ for 2 seconds. In the figure the black solid spectrum represents the Raman peak when the photopolymer layer was unexposed. The dash, dot and dash-dot, Raman spectra correspond to different illumination times of constant exposure doses.

From figure 4 it is clear that, as the photopolymerization occurs the acrylamide double bond breaks. As a result there is a decrease in the intensity of the peak.

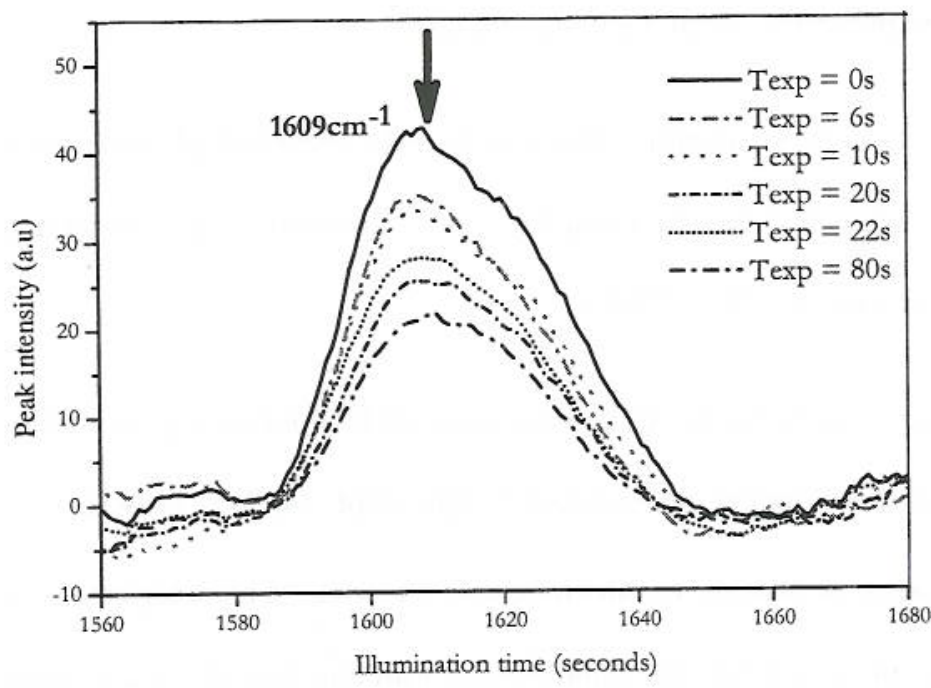

Figure 4. Raman spectra of photopolymer measured after exposing to a constant intensity of $2.5 \mathrm{~mW} / \mathrm{cm}^{2}$ Spectral peak at $1609 \mathrm{~cm}^{-1}$ corresponding to carbon-carbon double bond $(\mathrm{C}=\mathrm{C})$.

Figure 5 shows a graph of peak intensities for the Raman peak of the monomer double bonds, extracted from the spectrum, versus illumination time for a constant intensity. From the graph it can be seen that the consumption of monomer is monoexponential with illumination time. An exponential decay fit of the data gives the characteristic time constant for the decay of the monomer double bond.

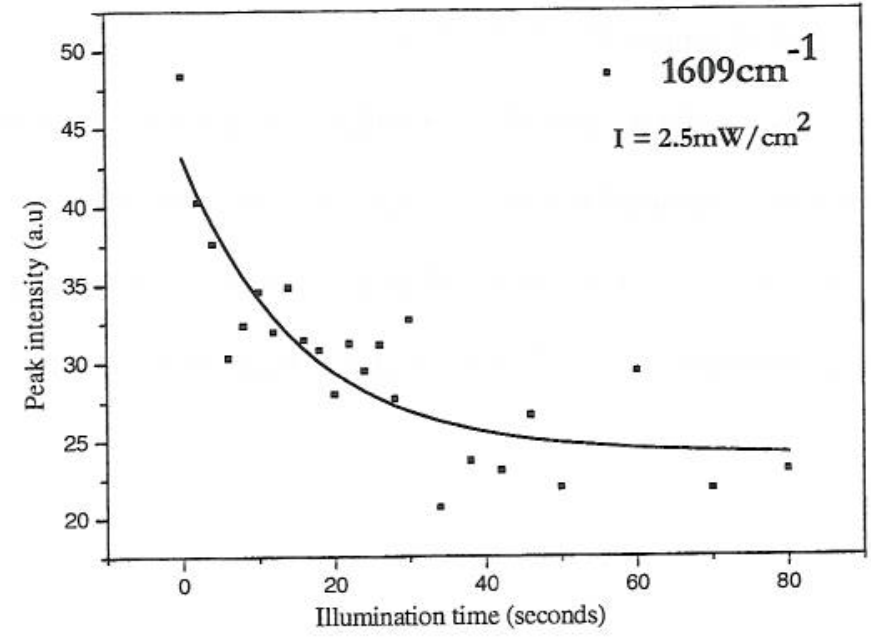

Figure 5. A graph of peak intensity versus illumination time corresponding to $1609 \mathrm{~cm}^{-1}$. The solid line shows the exponential fitting curve of the data shown as scattered points 
The time constant for the polymerization process was extracted and the polymerization rate constant calculated assuming the relation between the polymerization rate and the intensity is represented by equation (1) below [12].

$$
\begin{gathered}
\text { Slope }=1 / \mathrm{t}=\mathrm{k} \mathrm{I}_{0}^{1 / 2} \text { equation (1) } \\
\text { Where } \mathrm{k}=0.043 \mathrm{~s}^{-1}\left(\mathrm{~mW} / \mathrm{cm}^{2}\right)^{-0.5} \text { is the polymerization rate constant }
\end{gathered}
$$

A similar behavior in the kinetics was observed for the vinyl $\mathrm{CH}$ bending mode bond at $1284 \mathrm{~cm}^{-1}$. Using the same procedure the data at $1284 \mathrm{~cm}^{-1}$ was extracted and fitted using the same fitting function. The time constant of the decay of the vinyl $\mathrm{CH}$ bending mode peak was observed to be similar to that of the monomer carbon-carbon double bond decay time constant. The results are shown in the figures 6 and 7.

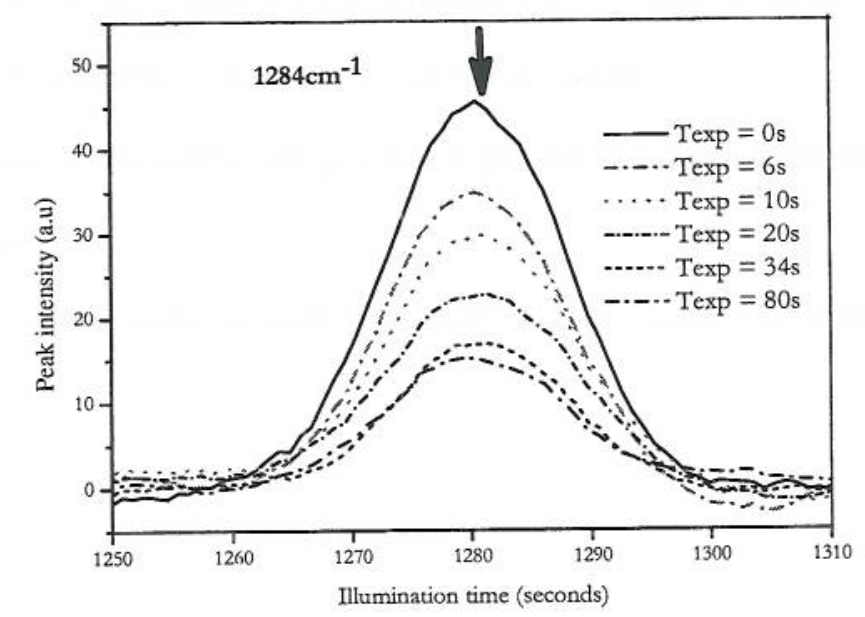

Figure 6. Raman spectra of photopolymer measured after exposing to a constant intensity of $2.5 \mathrm{~mW} / \mathrm{cm} 2$ Spectral peak at $1284 \mathrm{~cm}-1$ corresponding to carbon-hydrogen vinyl bond $(\mathrm{CH})$.

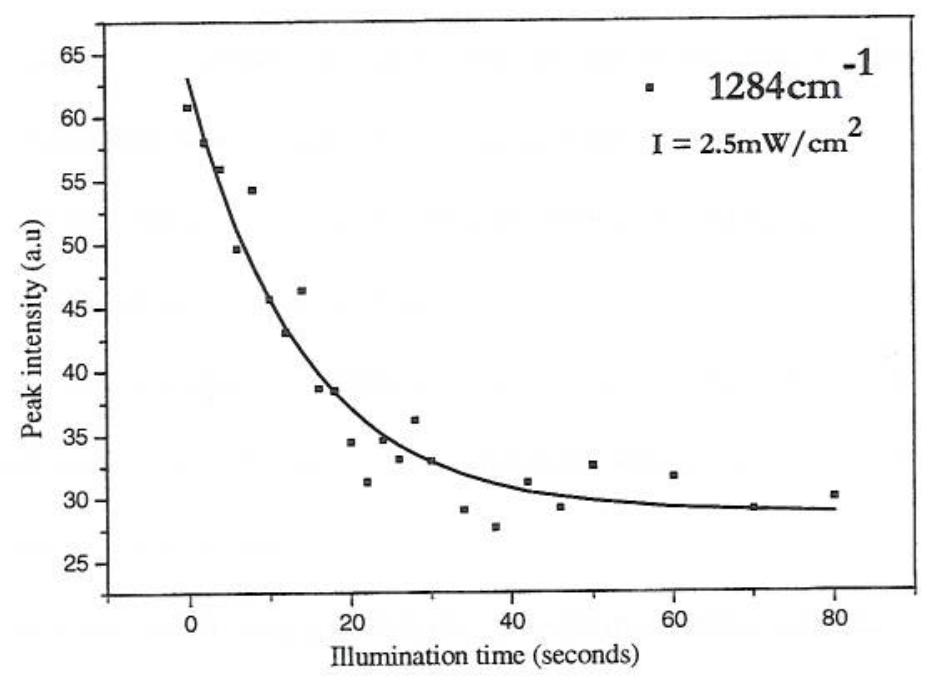

Figure 7. A graph of peak intensity versus illumination time corresponding to $1284 \mathrm{~cm}^{-1}$. The solid line shows the exponential fitting curve of the data shown as scattered points 
From the fits the decay time constant for consumption of monomer during polymerization was around 15 seconds. By substituting the value of time constant and exposure intensity in equation (1) the polymerization constant of the photopolymer with only one monomer is $0.043 \mathrm{~s}^{-1}\left(\mathrm{~mW} / \mathrm{cm}^{2}\right)^{-0.5}$. It's worth noticing that the two rates extracted from the data at $1609 \mathrm{~cm}^{-1}$ and at $1284 \mathrm{~cm}^{-1}$ are the same.

When compared to other photopolymers such as Du Pont's whose polymerization rate was characterized as $0.019 \mathrm{~s}^{-1} \mathrm{~mW}^{-0.5}$, the photopolymer under study has a faster polymerization rate.

The extracted polymerization rate is in order of two times faster than the one obtained by Neipp et al [13] for a similar acrylamide-based photopolymer system. But Neipp's figure depends on estimating diffusion time to be 30 seconds. In the present system somewhat faster rate was obtained by independent measurements and did not rely on assumed diffusion rates. It should also be borne in mind that the polymerization rate in this system was estimated under uniform photopolymerization. In holographic recording the actual polymerization rates are likely to be influenced by diffusion of additional monomer and a spatially varying supply of initiating molecules and could be even faster. Also variations in polymerization rates would be expected due to the non-identical formulations.

\section{CONCLUSIONS}

Characterization of the polymerization rate constant in an acrylamide-based photopolymer for holographic recording using Raman spectroscopy was presented. The consumption of monomer is seen to be monoexponential. A time constant from the linear fit of the natural logarithmic of the intensity peak corresponding to carbon-carbon double bond and carbon-hydrogen vinyl bond was obtained and the polymerization rate constant was determined as $0.043 \mathrm{~s}^{-1}\left(\mathrm{~mW} / \mathrm{cm}^{2}\right)^{-0.5}$. The polymerization rate constant in this photopolymer appears to be faster than in other commercial photopolymers for holographic recording.

\section{ACKNOWLEDGMENTS}

The authors would like to thank DIT for funding the project. FOCAS was funded under the Irish Government National Development Plan 2000-2006 with assistance from the European Regional Development Fund.

\section{REFERENCES}

[1]. S.Guntaka, V.Toal, S.Martin, "Holographically recorded diffractive optical elements for holographic and electronic speckle pattern interferometry", App.Opt., Vol. 41, No.35, pp.7475-7479, 2002.

[2]. R.T.Ingwall, D.A.Waldman, H.J.Caufal, D.Psaltis, G.T.Sincerbox, "Holographic data storage", Springer Series in Optical Sciences, New York, Vol.76, CH. Photopolymer systems, pp.171-197, 2000.

[3]. A.Tork, P.Nagtegaele, T.V.Galstian, "Reversible dye-doped holographic photopolymer materials for reconfigurable optical data storage", J.Synthtic Mat., Vol.127, pp.81-84, 2002.

[4]. J.T.Sheridan, F.T.O'Neill, J.V.Kelly, "Holographic data storage: Optimized scheduling using the nonlocal polymerization-driven diffusion model”, J.Opt.Soc.Am.B., Vol.21, No.8, pp.1443-1451, 2004.

[5]. S.Blaya, L.Carretero, R.F.Madrigal, A.Fimia, "Theoretical model of holographic grating formation in photopolymerizable dry films in slanted geometry", Opt. Comm. Vol. 173, pp. 423-433, 2000.

[6]. I.Naydenova, R.Jallapuram, R.Howard, S.Martin, V.Toal, "Investigation of the diffusion processes in a selfprocessing acrylamide-based photopolymer system”, J.Appl. Opt., Vol.43, No.14, pp. 2900-2905, 2004.

[7]. I.Aubrecht, M.Miler, I.Koudela, "Recording of holographic diffraction gratins in photopolymers: theoretical modeling and real-time monitoring of grating growth", J.Mod.Opt., Vol.45, No.7, pp.1465-1477, 1998.

[8]. W.S.Colburn, K.A.Haines, "Volume hologram formation in photopolymer materials", J.App.Opt., Vol.10, No.7, pp.1636-1641, 1971.

[9]. V.L.Colvin, R.G.Larson, A.L.Harris, M.L.Shilling, "Quantitative model of volume hologram formation in photopolymers", J.App.Phys., Vol.81, No.9, pp.5913-5923, 1997.

[10]. G.M.Karpov, V.V.Obukhovsky, T.N.Smirnova, V.V.Lemeshko, "Spatial transfer of matter as a method of holographic recording in photoformers", Opt.Comm., Vol.174, pp.391-404, 2000.

[11]. J.H.Kwon, H.C.Hwang, K.C.Woo, "Analysis of temporal behavior of beams diffracted by volume gratings formed in photopolymers”, J.Opt.Soc.Am.B, Vol.16, No.10, pp.1651-1657, 1999.

[12]. V. Moreau, Y. Renotte, Y. Lion, "Characterization of Du-Pont photopolymer: determination of kinetic parameters in a diffusion model”, Appl.Opt. Vol41, pp.3427-3435, 2002. 
[13]. C.Neipp, S.Gallego, M.Ortuno, A.Marquez, A.Belendez, I.Pascual, "Characterization of a PVA/acrylamide photopolymer: Influence of a cross-linking monomer in the final characteristics of the hologram", Opt.Comm., Vol.224, pp. 27-34, 2003.

[14]. S.Piazzolla, B.K.Jenkins, "First-harmonic diffusion model for holographic grating formation in photopolymers", J.Opt.Soc.Am.B, Vol.17, No.7, pp.1147-1157, 2000.

[15]. C.Baldock, L.Rintoul, S.F.Keevil, J.M.Pope, G.A.George, "Fourier transform Raman spectroscopy of acrylamide gels (PAGs) for radiation dosimetry” Phys.Med.Biol., Vol.43, pp.3617-3627, 1998.

[16]. A.I.Jirasek, C.Duzenli, C.Audet, J.Eldridge, "Characterization of monomer/crosslinker consumption and polymer formation observed in FT-Raman spectra of irradiated polyacrylamide gels", Phys.Med. Biol. Vol 46, pp. 151-165, 2001. 